\title{
Reconstruction of the sternal manubrium
}

\author{
Jarosław Kużdżał, MD, PhD, FETCS, ${ }^{\mathrm{a}}$ Janusz Warmus, MD, PhD, ${ }^{\mathrm{a}}$ Zbigniew Grochowski, MD, PhD, ${ }^{\mathrm{a}}$ and \\ Artur Gądek, MD, PhD, ${ }^{\mathrm{b}}$ Cracow, Poland
}

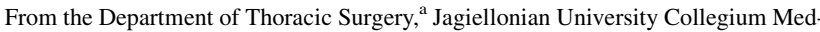
icum, John Paul II Hospital, Cracow, Poland; and the Department of Orthopaedics, ${ }^{\text {b }}$ Jagiellonian University Collegium Medicum, Cracow, Poland.

Disclosures: J.K. reports equity ownership in Medyeyna Praktyina and Techhot. Z.G. reports lecture fees from Boston Scientific. All other authors have nothing to disclose with regard to commercial support.

Received for publication Jan 8, 2014; revisions received Jan 27, 2014; accepted for publication Jan 31, 2014; available ahead of print March 15, 2014.

Address for reprints: Jarosław Kużdżał, MD, PhD, FETCS, Ulica Prądnicka 80, 31-202 Kraków, Poland (E-mail: j.kuzdzal@mp.pl).

J Thorac Cardiovasc Surg 2014;147:1986-8

$0022-5223 / \$ 36.00$

Copyright $(c) 2014$ by The American Association for Thoracic Surgery

http://dx.doi.org/10.1016/j.jtcvs.2014.01.040

Sternal chondrosarcoma and osteosarcoma are resistant to chemotherapy and radiation, so wide resection is the only curative option. Surgical margins need to be wide, necessitating resection not only of the upper sternum but also of the medial parts of both clavicles and upper ribs with adjacent intercostal muscles. This results in a large postresectional defect of the anterior chest wall (Figure 1, $A$ and $B$ ). The reconstruction should restore the rigidity of the chest wall while at the same time allowing for its efficient respiratory movements. If resection of the clavicles includes the attachments of the costoclavicular ligaments, this may
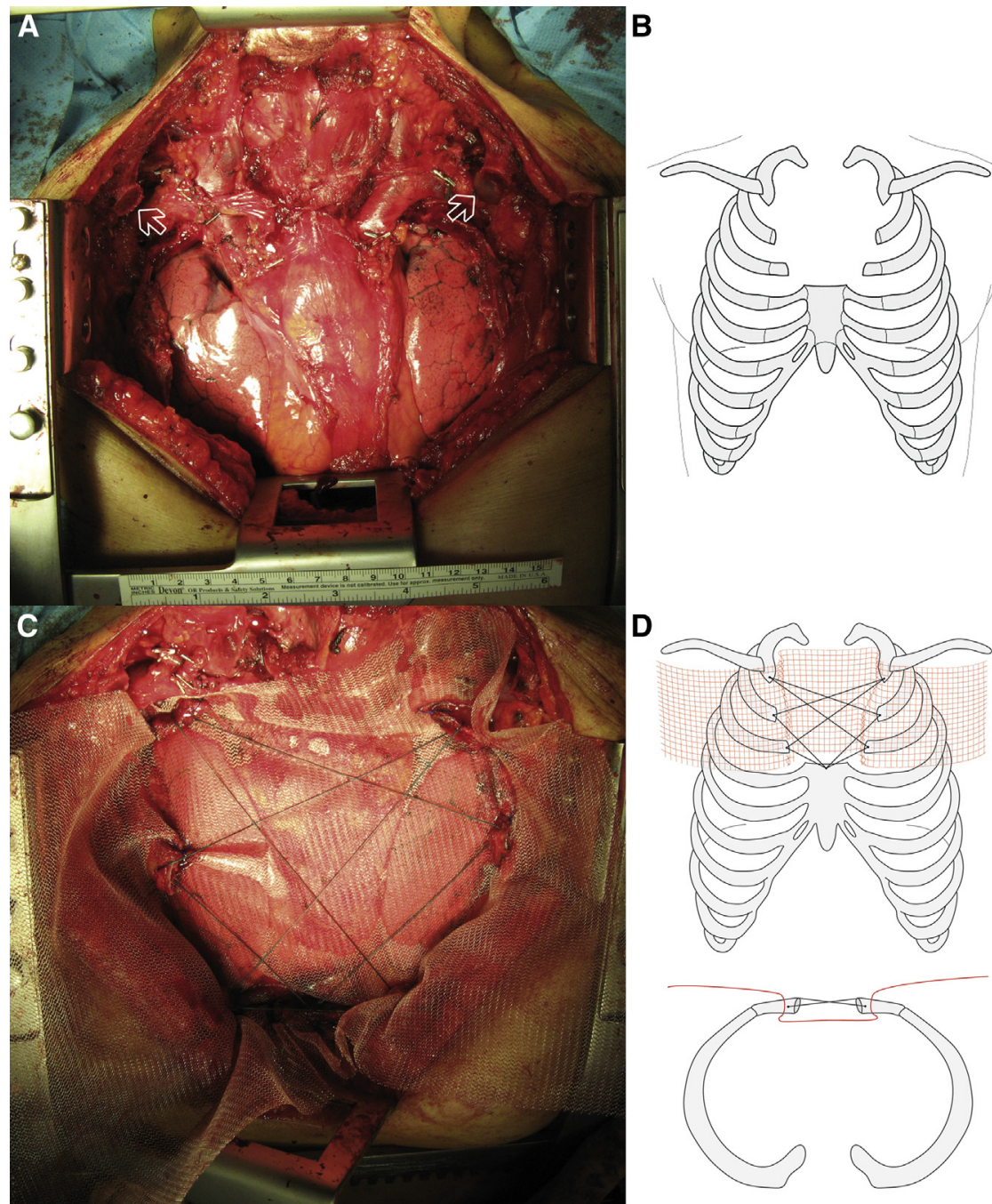

FIGURE 1. Intraoperative view (A) and schematic drawing (B) of the large postresectional defect of the anterior chest wall. Arrows in panel A show the ends of resected clavicles. The posterior layer of the mesh and sutures holding together the ends of resected ribs are shown in the intraoperative view (C) and schematic drawing (D) from a later point in the procedure; excessive parts of the mesh will form the anterior layer of the repair. 


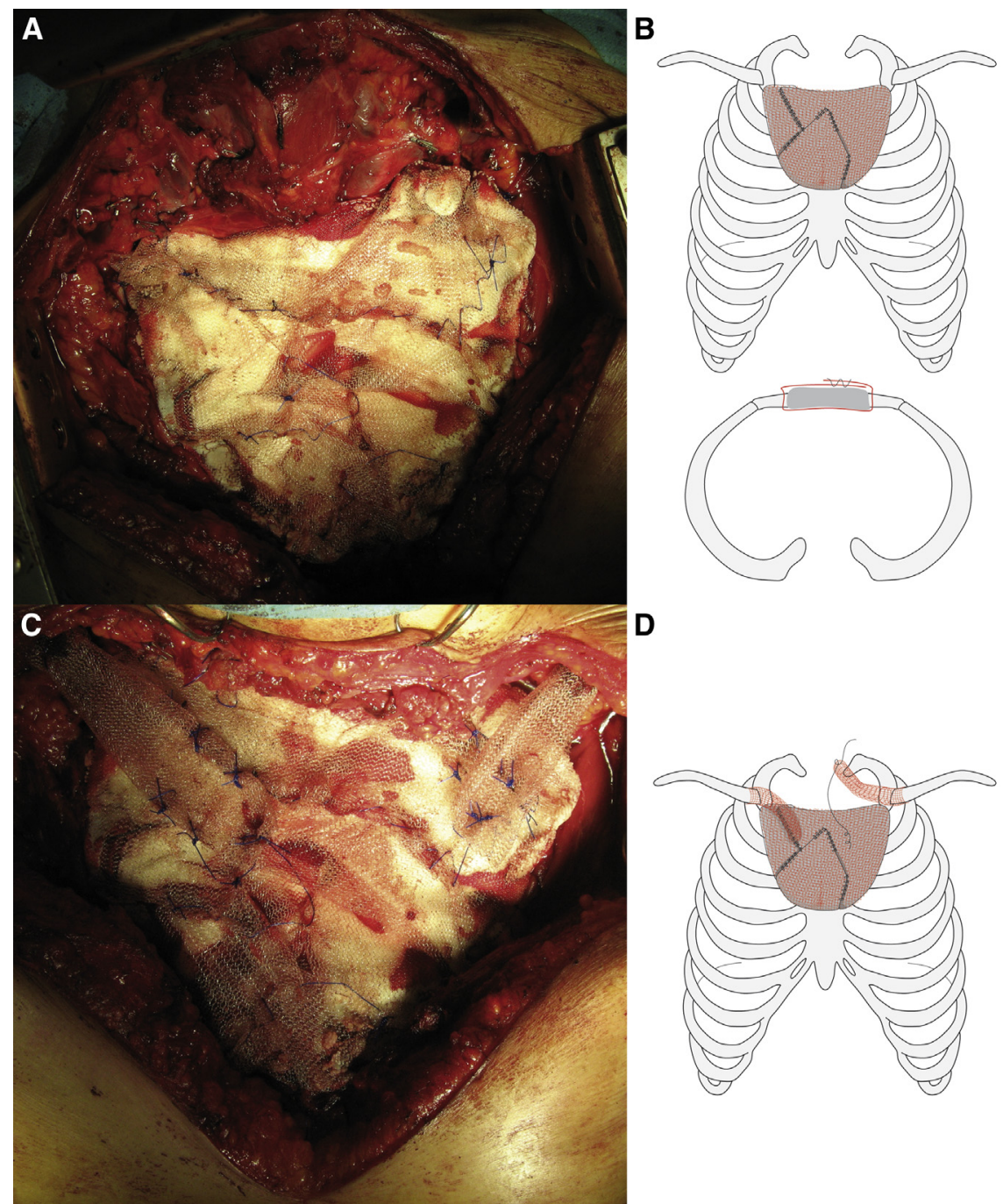

FIGURE 2. Intraoperative view (A) and schematic drawing (B) of the complete sandwich reconstruction. Reconstruction of the medial parts of the clavicles is presented in the intraoperative view (C) and schematic drawing (D) from a later point in the procedure.

result in inadequate movements of the remaining clavicles and possible collision with the subclavian veins. To prevent this, restoration of integrity of the shoulder girdle is advisable. Although several techniques have been described-including titanium bars, autologous or cryopreserved ribs, meshes, and patches-none of them meet all the criteria for optimal reconstruction.

The mainstay of the "sandwich" technique is the use of 2 layers of heavy polypropylene mesh with methyl methacrylate bone cement between them. The combination of polypropylene mesh and methyl methacrylate was first described in the 1970 s. $^{1}$

The mesh is placed on the anterior surface of the mediastinum, and small incisions are made in it to allow the medial ends of resected ribs to pass through the mesh. Next, No. 2 Dacron polyester sutures are placed through the ends of the ribs, crossing each other in a shoelace fashion (Figure 1,C and $D$ ). These sutures keep the ribs in the right position during the repair and also provide additional force to prevent them from breaking out of the methacrylate plate thereafter. It is important to adjust the mesh so that it is stretched with some tension. The mesh is then fixed on both sides to the intercostal muscles and rib ends with continuous sutures. The excess mesh on both sides is left to form the anterior layer of the sandwich.

Once the concave mesh providing a formwork for the bone cement is ready, the methyl methacrylate should be prepared. It is crucial to have the operative field prepared in every detail before cement preparation, because the cement is only semiliquid for about 3 minutes. Strict adherence to the instructions of the manufacturer is essential during the mixing of the 2 components. The cement is poured into the mesh form in an amount 
sufficient to produce a $1-$ to $1.5-\mathrm{cm}$ thick layer, with the intercostal sutures embedded in it. The excess flaps of the mesh are bent to form the anterior layer of the sandwich (Figure 2, A and B). Some overlaps and folds in the anterior layer are unavoidable. Hardening of the cement is an exothermic reaction, and cooling of the surrounding tissue may be advisable. It is important to keep modeling the sandwich constantly during hardening, because it cannot be reshaped once it has set. Special attention should be paid to supporting the area of the reconstructed sternal notch with a finger or a spatula, because there is a risk of compression of the innominate veins if the cement plate is positioned too deep.

The last step of the reconstruction is fixing the ends of resected clavicles to the neosternum. This is done with 2 pieces of the polypropylene mesh formed into a tubular shape and fixed to the clavicles with nonabsorbable sutures passed through holes drilled in the bone. The medial ends of these tubes are sutured to mesh of the anterior mesh layer (Figure 2, $C$ and $D$ ). Fibrocyte ingrowth and collagen production form a strong but flexible structure, which enables unhampered movement of the shoulder girdle while preventing excessive mobility of the free ends of resected clavicles.

Most of the articles on sternal reconstruction are case reports, and only a few report small case series. ${ }^{2,3}$
This presentation is therefore based mainly on our personal experience with 6 patients.

Because of the specific physical characteristics of the material used, the presented technique is an interesting option for sternal reconstruction. The polypropylene mesh has a high tensile strength and is flexible. In addition, the risk of seroma formation is low and fibroblasts grow into the mesh, producing a resistant, scarlike structure. In contrast, methyl methacrylate has a high crushing strength and is rigid. Both materials are easily tailored to the size and shape of the defect, have good tissue compatibility, and are inexpensive.

The presented technique of reconstruction allows the tailored replacement of the removed segment of the anterior chest wall. The double mesh-reinforced methacrylate plate provides good protection of the mediastinal organs while enabling unhampered breathing.

\section{References}

1. Eschapasse H, Gaillard J, Fournial G, Berthoumieu F, Henry E, Hornus E, et al. [Use of acrylic prosthesis for the repair of large defects of the chest wall (author's transl)]. Acta Chir Belg. 1977;76:281-5. French.

2. Kilic D, Gungor A, Kavukcu S, Okten I, Ozdemir N, Akal M, et al. Comparison of Mersilene mesh-methyl metacrylate sandwich and polytetrafluoroethylene grafts for chest wall reconstruction. J Invest Surg. 2006;19:353-60.

3. McKenna RJ Jr, Mountain CF, McMurtrey MJ, Larson D, Stiles QR Current techniques for chest wall reconstruction: expanded possibilities for treatment. Ann Thorac Surg. 1988;46:508-12.

\title{
Novel repair of a defect in the cervical trachea with a thymus pedicle flap
}

\author{
Kimihiro Shimizu, MD, PhD, Toshiteru Nagashima, MD, Yoichi Ohtaki, MD, PhD, and \\ Izumi Takeyoshi, MD, PhD, Maebashi, Japan
}

The reconstruction of a defect in the trachea remains challenging for thoracic surgeons. Although primary end-to-end anastomosis has been reported to permit successful resection of the adult trachea, an autologous tissue graft is usually required to repair the defect in situations where complete resection and end-to-end anastomosis appear

From the Department of Thoracic and Visceral Organ Surgery, Gunma University Graduate School of Medicine, Maebashi, Japan.

Disclosures: Authors have nothing to disclose with regard to commercial support.

Received for publication Nov 12, 2013; revisions received Jan 30, 2014; accepted for publication Jan 31, 2014; available ahead of print April 8, 2014

Address for reprints: Kimihiro Shimizu, MD, PhD, 3-39-15 Showa-machi, Maebashi, Gunma 371-8511, Japan (E-mail: kmshimizu@ gmail.com).

J Thorac Cardiovasc Surg 2014;147:1988-90 $0022-5223 / \$ 36.00$

Copyright $₫ 2014$ Published by Elsevier Inc. on behalf of The American Association for Thoracic Surgery

http://dx.doi.org/10.1016/j.jtcvs.2014.01.043 risky. We present a case in which we repaired a tracheacarotid artery fistula and reconstructed a defect in the cervical trachea by means of interposition of a thymus pedicle flap.

\section{CLINICAL SUMMARY}

A 56-year-old man with thyroid cancer invading the trachea underwent thyroidectomy with tracheal wedge resection and lymph node dissection. The patient underwent simultaneous tracheotomy because of suspected bilateral recurrent laryngeal nerve palsy. Ten days later, he was seen with endotracheal bleeding and was immediately taken to the operating room, where cardiopulmonary resuscitation was administered. The tracheostomy tube was removed, and a nasotracheal tube was inserted and advanced into the distal trachea. A reverse L-shaped 